\title{
THE EFFECTS OF ELASTO-PLASTIC BEHAVIOR AT THE CRACK TIP ON FATIGUE CRACK PROPAGATION
}

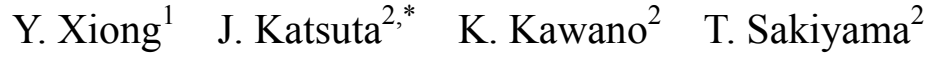 \\ ${ }^{1}$ Graduate School of Science and Technology, Nagasaki University, \\ 1-14 Bunkyo-machi, Nagasaki, 852-8521, Japan \\ ${ }^{2}$ Department of Structural Engineering, Faculty of Engineering, Nagasaki University, \\ 1-14 Bunkyo-machi, Nagasaki, 852-8521, Japan \\ (*Corresponding author: katsuta@st.nagasaki-u.ac.jp)
}

\begin{abstract}
Emphasis on physical meanings of the hysteresis loop denoting the relationship between loads and strains near the crack tip, variations of the loading tensile plastic load zone and the unloading compressive plastic load zone are studied respectively under various fatigue test conditions, and the effects on acceleration, deceleration and non-propagation during fatigue crack propagation are also studied. Two types of crack closure are obtained from tests, and the influence of each load zone of the hysteresis loop on fatigue crack propagation is evaluated. Result shows that load zones $P_{R P G} \sim P_{\max }$ and $P_{R C P G} \sim P_{C F}$ play an important role in the crack opening/closure behavior, and the fatigue crack propagates difficultly if the compressive plastic zone at the crack tip is not enough.
\end{abstract}

Keywords: Fatigue crack propagation, Crack tip, Opening/closure, Hysteresis loop, compressive plastic zone, Variable amplitude loading.

\section{INTRODUCTION}

The effect of elasto-plastic behavior at the crack tip on fatigue crack propagation has been known since Elber [1] affirmed crack closure phenomenon during fatigue crack propagation by experiment. An effective stress intensity factor range $\Delta K_{\text {eff }}\left(=K_{\max }-K_{\mathrm{op}}\right)$ was defined by an opening stress intensity factor $K_{\mathrm{op}}$, and the opening load $P_{\mathrm{op}}$ was often measured by ASTM $2 \%$ offset method or curve fitting method [2], as well as an unloading elastic compliance method brought by Kikukawa et al. [3]. Otherwise, Nisitani and Chen [4] defined an effective stress intensity factor range $\Delta K_{\text {eff }}$ $\left(=K_{\max }-K_{\mathrm{cl}}\right)$ by means of a closure stress intensity factor $K_{\mathrm{cl}}$, and the closure load $P_{\mathrm{cl}}$ was determined based on the inflexion point on the unloading compliance. But, loads $P_{\mathrm{op}}$ and $P_{\mathrm{cl}}$ were dependent on geometric criterion of the compliance curve obtained by global measurement techniques, and the method neglects the physical meaning of compliance change caused by plastic deformation at the crack tip. Recently, Toyosada and Niwa [5] investigated the physical change of the compliance during a load cycle by local measurement techniques, presented a concept of Re-tensile plastic zone's generated load $P_{\mathrm{RPG}}$ and established $\Delta K_{\mathrm{RPG}}\left(=K_{\mathrm{max}}-K_{\mathrm{RPG}}\right)$. He also presented a method for determining the special loads such as opening/closure loads through overlapping the original hysteresis loop near the crack tip on the loop which rotates at the coordinate origin by $180^{\circ}$. However, the above parameters cannot evaluate the effect of the compressive plastic zone at the crack tip on fatigue crack propagation, and there was an inaccuracy caused by the manual operation after experiment.

In this paper, by using global measurement techniques, the hysteresis loop of strains via loads denoting elasto-plastic behavior near the crack tip is obtained. Loads at inflexions on the hysteresis loop are calculated by differential and the hysteresis loop is divided into several physical load zones. Fatigue tests of CT specimen are carried out under variable amplitude loading. Emphasis on variations of the loading tensile and the unloading compressive plastic load zones during fatigue crack propagation, how the variations affect acceleration, deceleration and non-propagation 
phenomena are investigated in detail. By using of parameter $P_{\mathrm{CF}}$ that is presented in paper, the effect of the compressive plastic zone at the crack tip on fatigue crack propagation is ascertained.

\section{EXPERIMENTAL DETAILS}

\subsection{Material and conditions in fatigue test}

The fatigue test machine is a digital, hydraulic servo control machine with $200 \mathrm{kN}$ load capacity. Using a high-precision load cell and a digital dynamic strain meter as well as self-made measurement program, and strains both near the crack tip and on the back face and loads can be measured simultaneously with a sampling time $1 \mathrm{msec}$. The test process is monitored by a computer.

A CT specimen made of mild steel (JI-SM400B) is shown in Figure 1. The chemical composition and mechanical properties of the material are given in Table 1. Several groups of 5-piece (GL2mm) strain gages are glued on surfaces of specimen just along the direction of crack propagation, a cut-free strain gage nearest to the crack tip is always chosen automatically by the program, and the strain near the crack tip is measured. Under a sine tensile load with a frequency $10 \mathrm{~Hz}$, constant amplitude loading, block amplitude loading and $K_{\text {th }}$ tests are carried out. In constant amplitude loading tests, the maximum load is $20 \mathrm{kN}$ and the minimum load is $2 \mathrm{kN}$. In block amplitude loading tests, the minimum load is always $2 \mathrm{kN}$ and the maximum load changes at intervals of 50000 cycles. The load amplitudes from stage A to stage $\mathrm{F}$ are $2-20 \mathrm{kN}, 2-30 \mathrm{kN}, 2-20 \mathrm{kN}, 2-10 \mathrm{kN}, 2-20 \mathrm{kN}$, $2-30 \mathrm{kN}$, respectively. In $K_{\mathrm{th}}$ tests, the maximum load is always $20 \mathrm{kN}$ and the minimum load rises at intervals of $2.5 \mathrm{~mm}$ crack propagation length. The load amplitude at stage $\mathrm{A}$ is $2-20 \mathrm{kN}$. The increment is $2 \mathrm{kN}$ from $\mathrm{B}$ to $\mathrm{E}, 1 \mathrm{kN}$ from $\mathrm{F}$ to $\mathrm{K}, 0.5 \mathrm{kN}$ from $\mathrm{L}$ to $\mathrm{O}$, respectively. Finally, the load amplitude is about $18-20 \mathrm{kN}$ at $\mathrm{O}$.

Table 1. Chemical composition and mechanical properties of SM400B

\begin{tabular}{c|c|c|c|c|c|c|c}
\hline \multicolumn{4}{c|}{ Chemical compositions (wt. \%) } & \multicolumn{3}{c}{ Mechanical properties } \\
\hline $\mathrm{C}$ & $\mathrm{Si}$ & $\mathrm{Mn}$ & $\mathrm{P}$ & $\mathrm{S}$ & Yield stress & Tensile strength & Elongation \\
\hline 0.15 & 0.21 & 0.61 & 0.02 & 0.012 & 314 & 440 & 26 \\
\hline
\end{tabular}
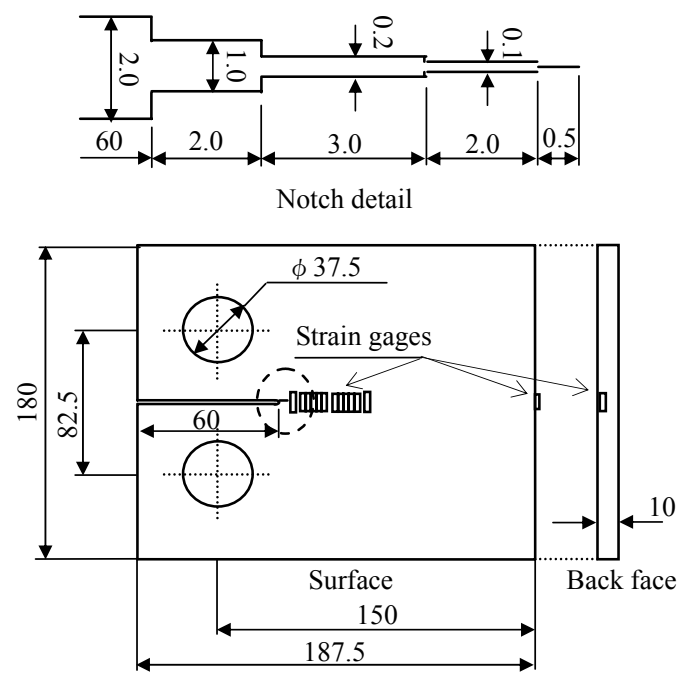

Figure 1. CT type specimen used in fatigue test 
The relationship between the compliance and the fatigue crack length is determined by other experiments. The compliance is obtained from the relationship between loads and strains on the back surface of CT specimen (Figure 2). The fatigue crack length is measured by beach mark method. Their relation is given by a curve in Figure 3. The crack propagation length in fatigue test is calculated from equation (1) based on Figure 3 [6].

$$
C_{p}=\frac{1}{E t} \times\left\{1+\frac{0.25}{a_{i} / W}\right\} \times\left\{\frac{1+a_{i} / W}{\left(1-a_{i} / W\right)^{2}}\right\} \times\left\{0.0901+1.2787 \frac{a_{i}}{W}+0.1854\left(\frac{a_{i}}{W}\right)^{2}-1.6939\left(\frac{a_{i}}{W}\right)^{3}+0.8617\left(\frac{a_{i}}{W}\right)^{4}+0.983\left(\frac{a_{i}}{W}\right)^{5}\right\}
$$

where $C_{\mathrm{p}}$ is the compliance, $E$ Young's Modulus, $t$ and $W$ the thickness and the width of CT specimen $(\mathrm{mm}), a_{\mathrm{i}}$ the crack length (mm).

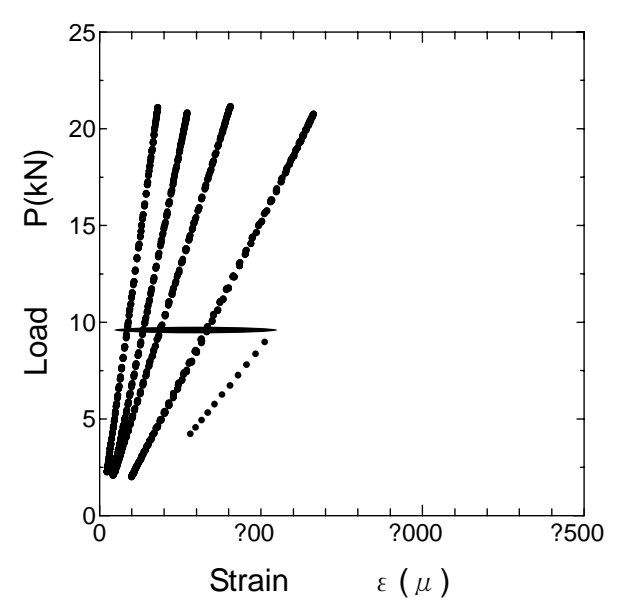

Figure 2. The example of relation between loads and strains on the back-face

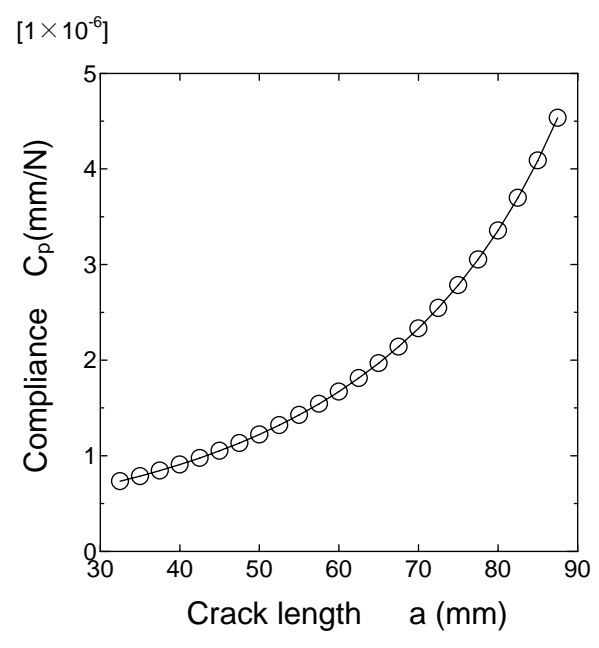

Figure 3. Relationship between compliance and fatigue crack length

\subsection{Measurement of physical load zones on hysteresis loop}

The relationship between loads and strains near the crack tip under given cycles is monitored by program. Figure 4 provides a series of results measured step by step during fatigue crack propagation. For each result, subtracting the unloading elastic strains from strains near the crack tip and magnifying them, a hysteresis loop is obtained as shown in Figure 5 (middle). But it is difficult to determine loads at physical inflexions from the original hysteresis loop. In order to evaluate the elasto-plastic behavior at the crack tip quantitatively, the hysteresis loop is divided into loading and unloading parts and the least square method is applied for expression by functions as shown in Figure 5(left and right). Figure 6 gives the relationships between $P$ and $d \varepsilon^{\prime} / d p$, and between $P$ and $d^{2} \varepsilon^{\prime} / d p^{2}$.

Based on physical study in the Ref. [7], the maximum in the first differential of unloading part is defined as the closure load $P_{\mathrm{cl}}$, and the minimum in the second differential of loading part is defined as Re-tensile plastic zone's generated load $P_{\mathrm{RPG}}$. The reason for the former is that regeneration of Re-compressive plastic zone at the crack tip leads $d \varepsilon^{\prime} / d p$ raise and the increase in ligament after crack closure makes $d^{2} \varepsilon^{\prime} / d \mathrm{p}^{2}$ decrease during unloading process. The reason for the latter is that $d \varepsilon^{\prime} / d \mathrm{p}$ increases and $d^{2} \varepsilon^{\prime} / d \mathrm{p}^{2}$ decreases before crack open, but $d \varepsilon^{\prime} / d \mathrm{p}$ and $d^{2} \varepsilon^{\prime} / d \mathrm{p}^{2}$ increase simultaneously with Re-tensile plastic zone generates during loading process. 


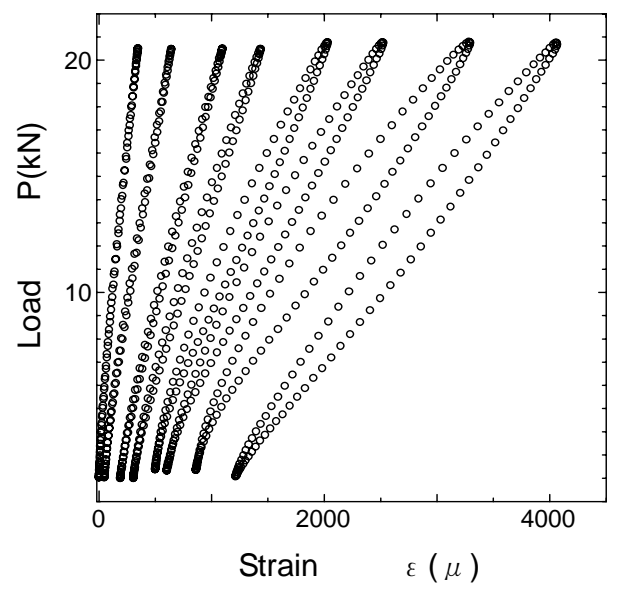

Figure 4. The examples of relation between loads and strains near the fatigue crack tip

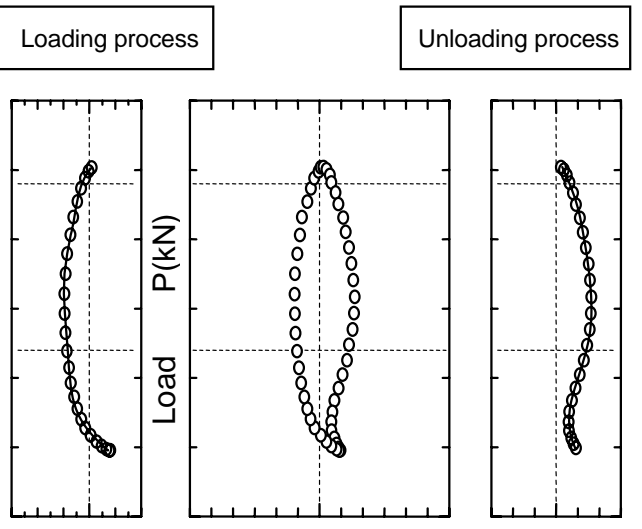

Subtract Strain $\Delta \varepsilon(\mu)$

Figure 5. An example of separated hysteresis loop to make functions

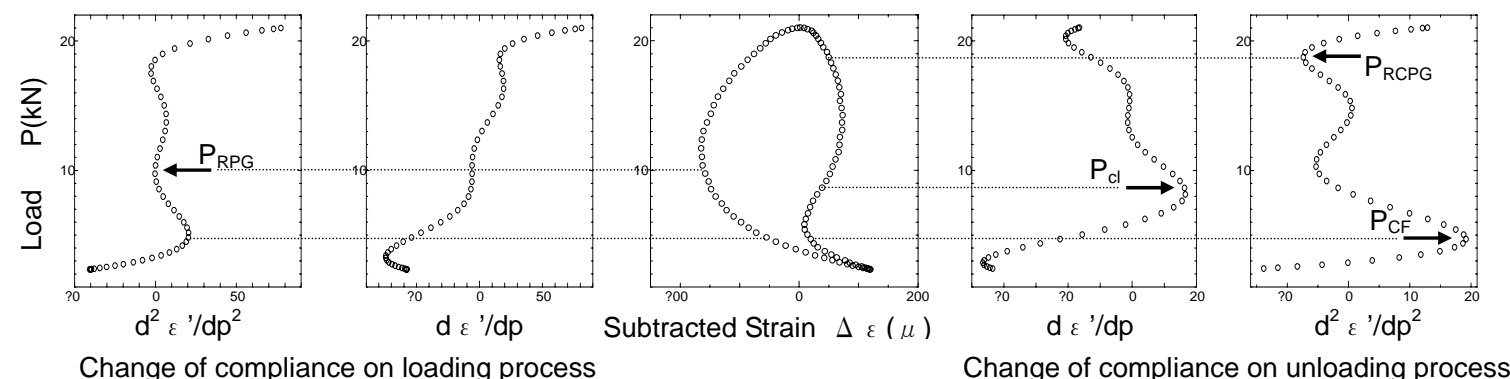

Figure 6. Quantitative calculation of $P_{\mathrm{RCPG}} P_{\mathrm{RPG}} P_{\mathrm{cl}}$ and $P_{\mathrm{CF}}$

In addition, the minimum in the second differential of unloading part is defined as Re-compressive plastic zone's generated load $P_{\text {RCPG }}$. But there is extreme point within zone $P_{\mathrm{cl}} \sim P_{\min }$ if the differential of compliance is carried out. The growth rate of the Re-compressive plastic zone from $P_{\mathrm{cl}}$ to the extreme point is slower than that in zone $P_{\mathrm{RCPG}} \sim P_{\mathrm{cl}}$, and the growth of crack closure is dominant, so $d \varepsilon^{\prime} / d \mathrm{p}$ decreases and $d^{2} \varepsilon^{\prime} / d \mathrm{p}^{2}$ increases. As unloading to the extreme point, that crack close will not progress due to the crack surfaces contact, therefore, $d \varepsilon^{\prime} / d \mathrm{p}$ and $d^{2} \varepsilon^{\prime} / d \mathrm{p}^{2}$ decrease simultaneously. Hereby, the extreme point is defined as a crack closure finish load $P_{C F}$ in this paper. Consequently, the zone from $P_{\mathrm{RPG}}$ to $P_{\max }\left(\Delta P_{\mathrm{PRG}}\right)$ indicates the loading tensile plastic load zone, the zone from $P_{\max }$ to $P_{\mathrm{RCPG}}$ the unloading elastic load zone, the zone from $P_{\mathrm{RCPG}}$ to $P_{\mathrm{CF}}\left(\Delta P_{\mathrm{RCF}}\right)$ the unloading compressive plastic zone, and the zone from $P_{\mathrm{CF}}$ to $P_{\min }$ the hysteresis loop tail.

\section{TEST RESULTS AND ANALYSIS}

\subsection{In the case of constant amplitude loading}

Figure 7 shows a part of test results under constant amplitude loading. Because of $0.1 \mathrm{~mm}$ width pre-crack on the bottom of saw notch, a small load causes yielding at the crack tip in the initial stage of fatigue crack propagation. At this time, the value $P_{\mathrm{RCPG}}$ is in the high load region, but the values $P_{\mathrm{RPG}}, P_{\mathrm{cl}}$ and $P_{\mathrm{CF}}$ are in the low load region as shown in Figure $7(\mathrm{~b})$, and the hysteresis loop tail is not formed as shown in Figure $7(\mathrm{a})(1)$. When the value $P_{\mathrm{RPG}}, P_{\mathrm{cl}}$ and $P_{\mathrm{CF}}$ rise gradually, the hysteresis loop tail enlarges gradually as shown in Figure 7(a)(2) and (3), and the fatigue crack begins to propagate. When each of the value $P_{\mathrm{RCPG}}, P_{\mathrm{RPG}}, P_{\mathrm{cl}}$, and $P_{\mathrm{CF}}$ tends to constants, the 
hysteresis loop tail are obvious as shown in Figure 7(a)(4),(5) and (6), and the fatigue crack propagates stably. Thereafter, the value $P_{\mathrm{RPG}}, P_{\mathrm{cl}}$, and $P_{\mathrm{CF}}$ decrease, the crack difficult to close as shown in Figure 7(a)(7) and (8), and the fatigue crack propagates fast. Therefore, it is considered that the change in size of the hysteresis loop tail is due to the influence of tensile deformed layer that remains on the crack surface as the fatigue crack propagates, which was described by Elber [1].

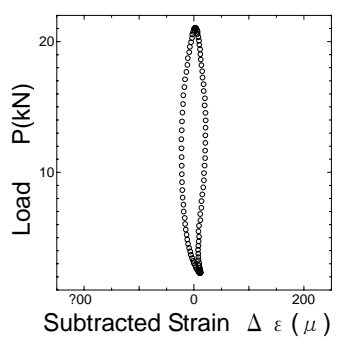

(1)

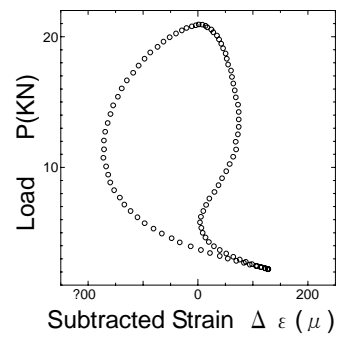

(5)

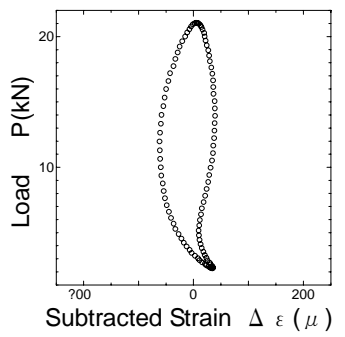

(2)

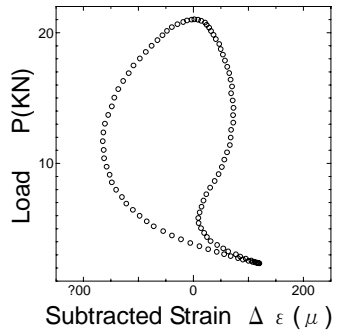

(6)

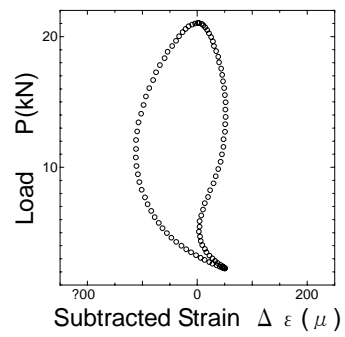

(3)

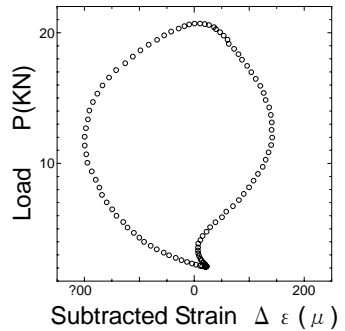

(7)

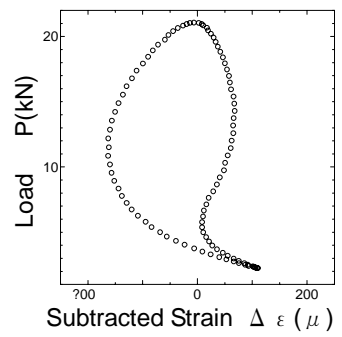

(4)

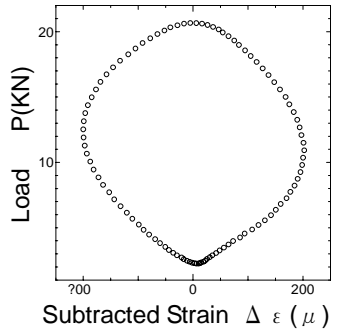

(8)

(a) Change of hystersis loops during fatigue crack propagation

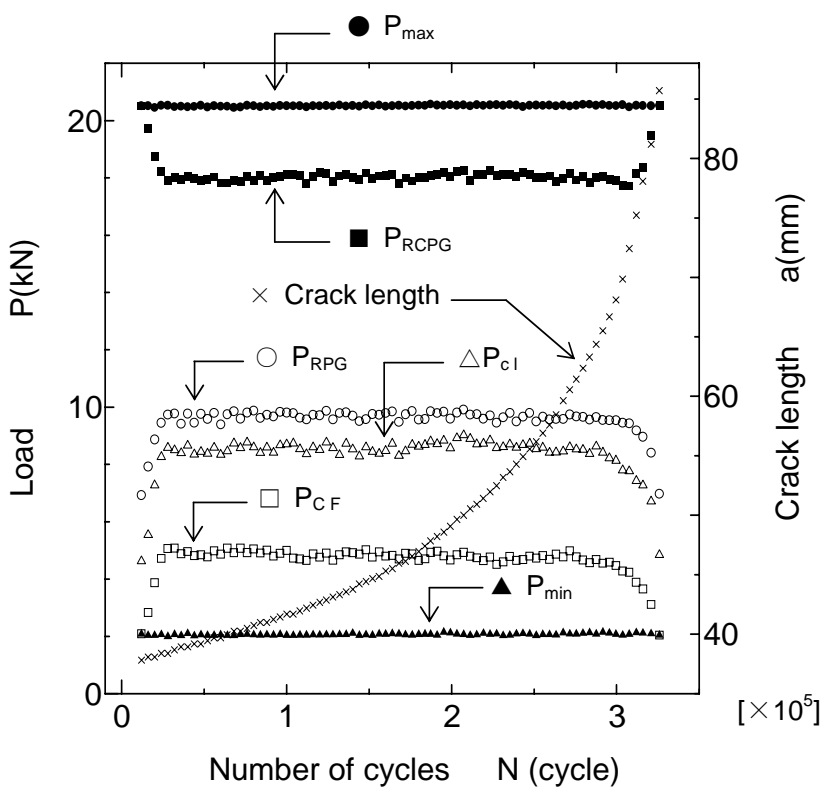

(b) The relationship between loads and fatigue crack length

Figure 7. Results of constant amplitude loading test

\subsection{In the case of block amplitude loading}

Figure 8 is a part of test results under block amplitude loading. Figure $8(a)(1)(3)(4)(5)(6)(7)$ indicate the characteristics of the hysteresis loops in each stage when the crack grows stably. Because the test condition in the stage $\mathrm{A}$ is the same as that under constant amplitude loading, the test results are the same. Entering stage $\mathrm{B}$, in the early stage of the maximum load $P_{\max }$ rising to $30 \mathrm{kN}, P_{\mathrm{RPG}}, P_{\mathrm{cl}}$ and $P_{\mathrm{CF}}$ decrease temporarily, the hysteresis loop tail becomes small as shown in 
Figure 8(a)(2), and the crack propagation shows acceleration. Because of a large tensile deformed zone forms at the crack tip when the overload is applied, the crack tip opens fully. After that, the tensile deformed layer on the crack surface becomes thick gradually with the crack propagation under high amplitude loads, thus make the crack close easy. Therefore, the value $P_{\mathrm{RPG}}, P_{\mathrm{cl}}$ and $P_{\mathrm{CF}}$ rise to constants in this stage. But in the stages $\mathrm{C}$ and $\mathrm{E}$, the zone from $P_{\mathrm{RCPG}}$ to $P_{\mathrm{cl}}$ reduces, the hysteresis loop tail lengthens as shown in Figure 8(a)(4) and (6). It is considered due to the effect of the thick residual tensile deformed layer that remains on the crack surface in the stage B make the crack close easy, thus the crack propagation shows deceleration. Entering the stage $\mathrm{D}$, the value $P_{\max }$ is close to the value $P_{\mathrm{RPG}}$ in the stage $\mathrm{C}$, and the value for the zone from $P_{\mathrm{RCPG}}$ to $P_{\mathrm{cl}}$ is almost zero, which means there is only elastic deformation at the crack tip under low amplitude loads as shown in Figure 8(a)(5), thus the crack propagation shows non-propagation. In the stage F, the zones $\Delta P_{\mathrm{RPG}}$ and $\Delta P_{\mathrm{RCF}}$ increase with the maximum load $P_{\max }$ increasing again and the hysteresis loop tail becomes small as shown in Figure $8(\mathrm{a})(8)$, thus the fatigue crack propagates speedily again.

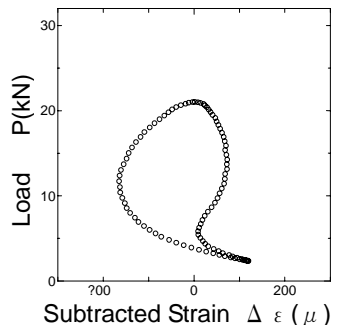

(1)

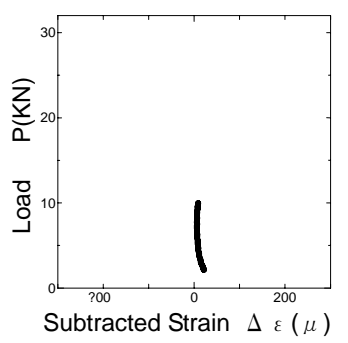

(5)

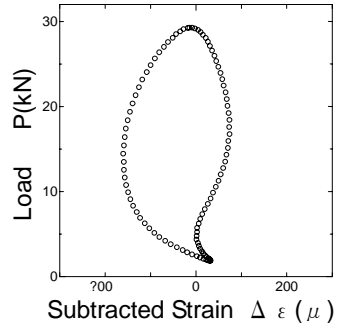

(2)

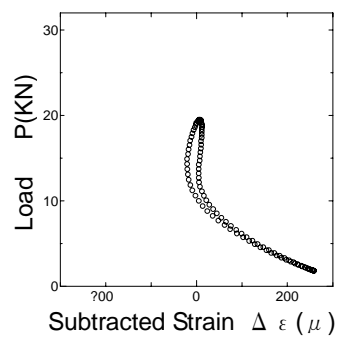

(6)

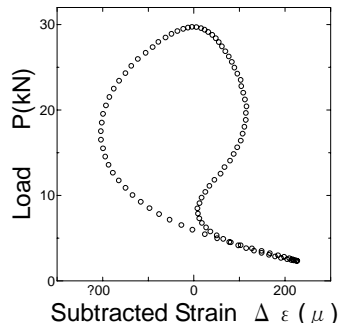

(3)

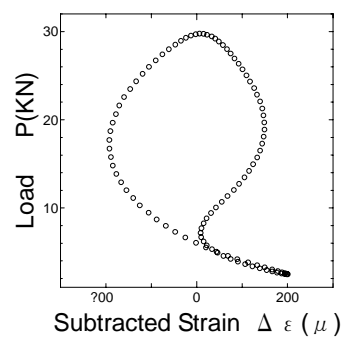

(7)

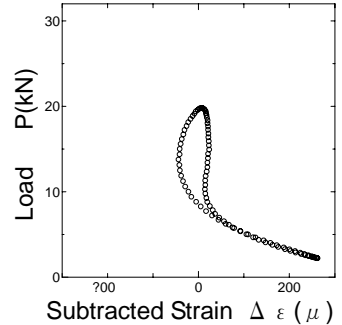

(4)

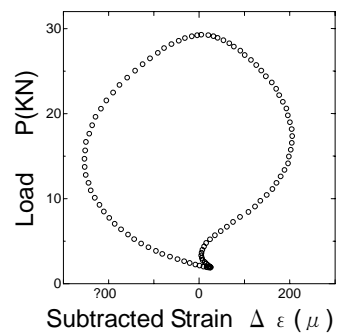

(8)

(a) Change of hystersis loops during fatigue crack propagation

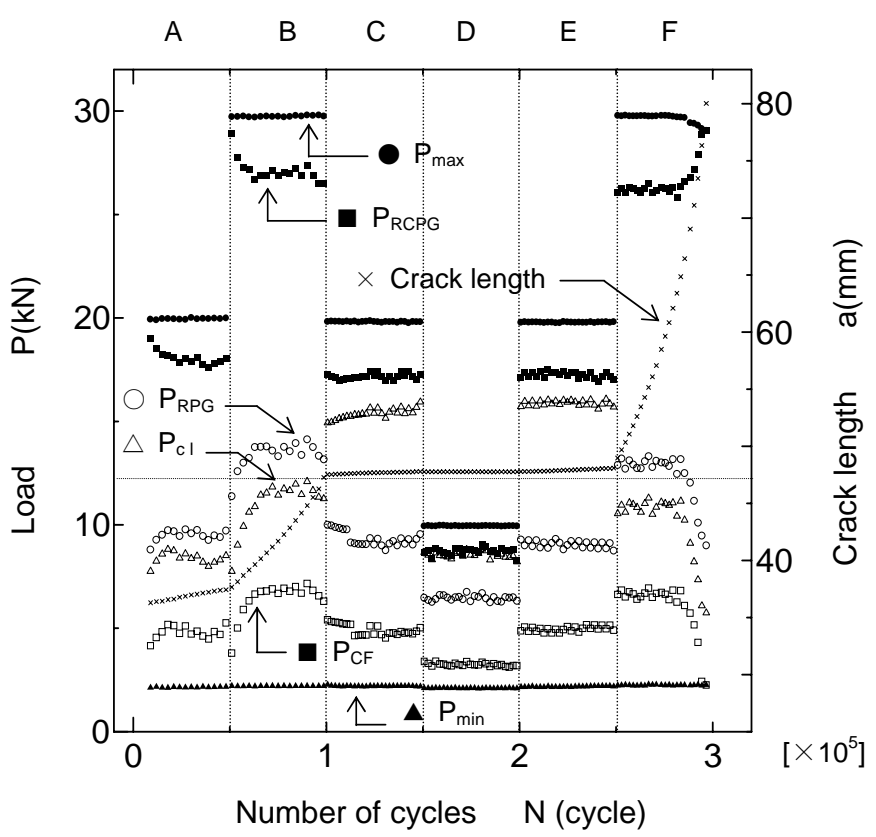

(b) The relationship between loads and fatigue crack length

Figure 8. Results of block amplitude loading test 
In addition, there is a formula for CT specimen according to fracture mechanics,

$$
K=\frac{P}{t \sqrt{W}} f\left(\frac{a}{W}\right)
$$

calculating the stress intensity factors by the loads in Figure $8 \mathrm{~b}$ a linear relationship is obtained,

$$
\left(K_{\max }-K_{R P G}\right) /\left(K_{R C P G}-K_{C F}\right)=\alpha
$$

and then the following equation is achieved,

$$
\Delta K_{R P G}=\alpha \Delta K_{R C F}
$$

It indicates that $\Delta K_{\mathrm{RPG}}$ decreases with $\Delta K_{\mathrm{RCF}}$ decreasing, or the crack propagates difficultly.

It is observed from the experiments, due to the increase of load amplitude, the residual tensile plastic deformed layer on the crack surface becomes thick, the crack surfaces contact completely when the load is unloaded to $P_{\text {CF. }}$. Consequently, $P_{\text {CF }}$ plays an action of shielding the crack tip. It have been clarified that the shielding action increases with the crack closure increasing.

\subsection{In the case of $K_{\text {th }}$ test}

Figure 9(a) shows hysteresis loops of some stage in the $K_{\text {th }}$ test. From the figure it is observed once the hysteresis loop becomes small, the hysteresis loop tail disappears gradually. It is known from Figure 9(b) they are different from those under block amplitude loading (decreasing maximum load), the value $P_{\text {RPG }}$ rises gradually and approaches $P_{\max }$, but the value $P_{\mathrm{cl}}$ approaches $P_{\min }$, and the fatigue crack propagation rate reduces from deceleration to non-propagation. This is because the thickness of the residual tensile deformed layer is almost the same at each stage of fatigue crack propagation in the case of the constant $P_{\max }$. Therefore, the crack propagation decelerates when the hysteresis loop tail disappearing, with the minimum load $P_{\min }$ increasing gradually. It means the shielding action of $P_{\mathrm{CF}}$ decrease to the minimum, or the value $P_{\mathrm{CF}}$ coincides with $P_{\min }$. But, when the minimum load rises to the preceding unloading elastic load zone, the crack opening is small in the subsequent loading process. Therefore the hysteresis loop shows no evident of opening at the crack non-propagation stage. The above characteristic is the same as that under block amplitude loading. It is known the fatigue crack propagates difficultly if there is not sufficiently compressive plastic zone at the crack tip.

\section{DISCUSSION}

Based on the test results, there are two types of crack closure that are closure-free and closure-affected respectively, and the open/closure patterns of the crack tip in different load zones of the hysteresis loop given in Figure10. Figure 10(a) and (b) denote an example of fatigue crack deceleration stage under $K_{\text {th }}$ tests and block amplitude loading, respectively.

After loading from $P_{\min }$, to the former, the crack tip opens gradually and it opens completely when the load reaches $P_{\text {op }}$. To the latter, closed crack surface opens gradually as the load reaches $P_{\mathrm{CF}}$, and the crack tip opens completely when the load reaches $P_{\mathrm{op}}$. Once the load exceeds the load point $P_{\mathrm{RPG}}$, the residual compressive stress acted at the crack tip releases completely and the Re-tensile plastic zone begins to form (If unloading begins before $P_{\mathrm{RPG}}$, the crack tip is in elastic status which is the same as the stage D under block amplitude loading). As the load continues to increase and reaches $P_{\max }$, the tensile plastic deformation at the crack tip reaches the maximum, and the crack propagates during this process. In the following unloading process, through the unloading elastic 


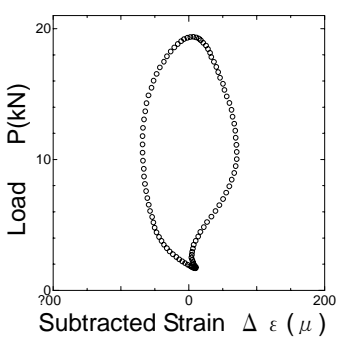

(1)

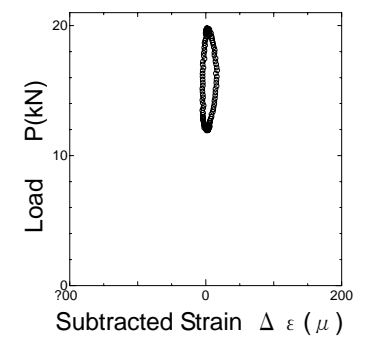

(5)

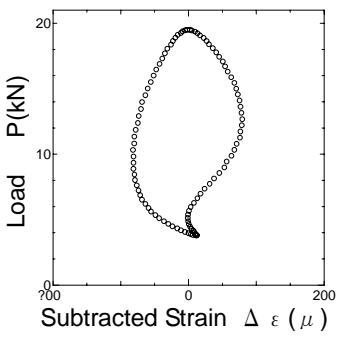

(2)

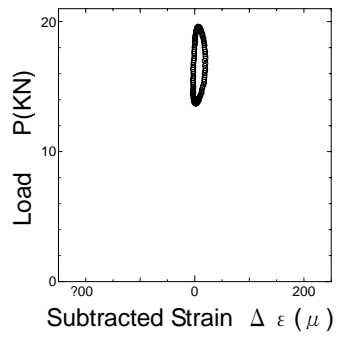

(6)

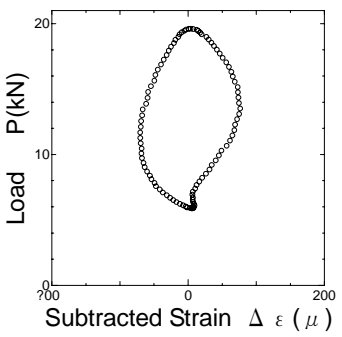

(3)

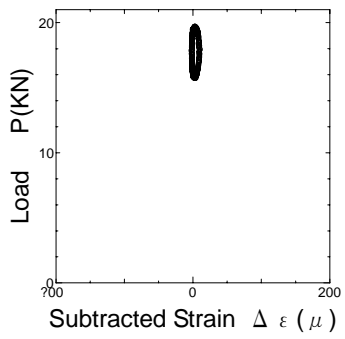

(7)

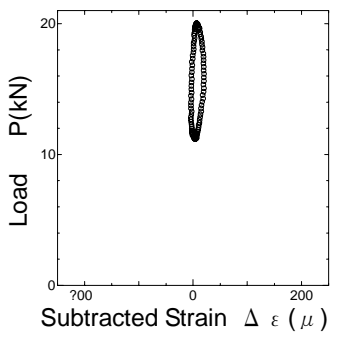

(4)

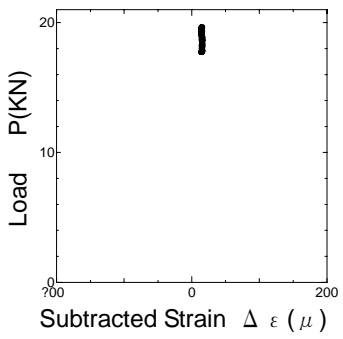

(8)

(a) Change of hystersis loops during fatigue crack propagation

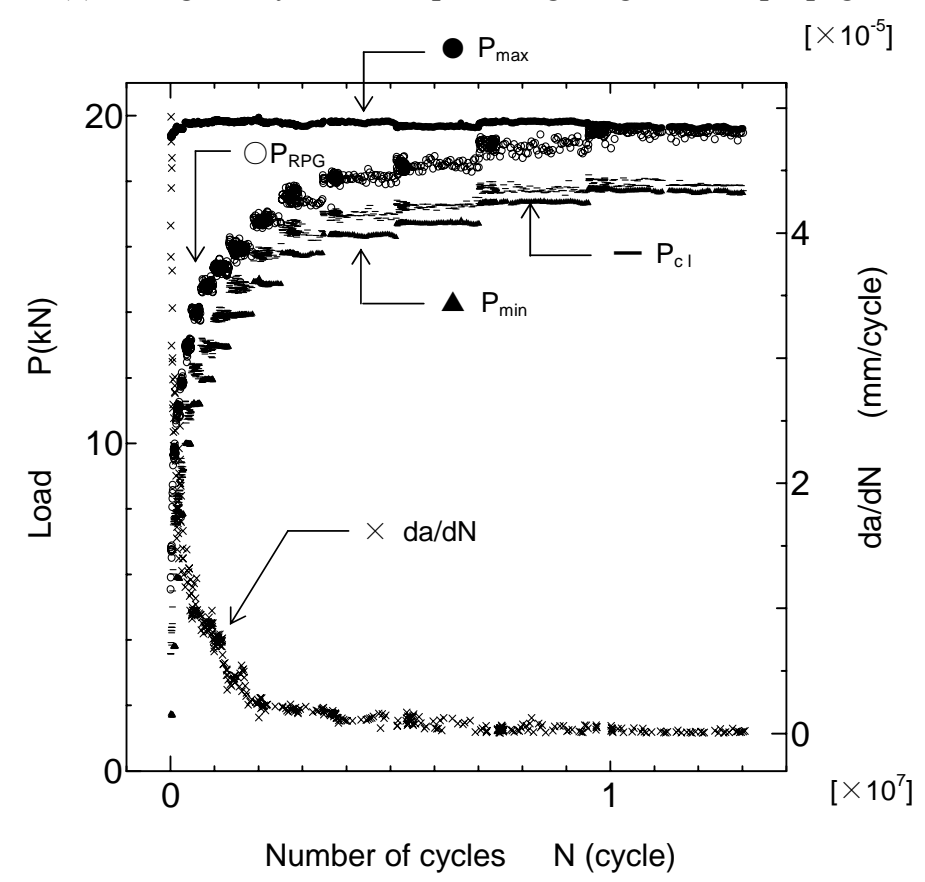

(b) The relationship between loads and fatigue crack propagation data

Figure 9. Results of $\mathrm{K}_{\mathrm{th}}$ test

zone $P_{\max } \sim P_{\mathrm{RCPG}}$ (If loading before $P_{\mathrm{RCPG}}$, the crack tip is in elastic status which is the same as the final stage in $K_{\text {th }}$ test), the Re-compressive plastic zone at the crack tip begins to form and the crack tip begins to close as the unloading reaches $P_{\mathrm{cl}}$. After that, to the former, the crack tip close completely when the load is unloaded to $P_{\min }$, and the actual amplitude at the crack tip is equivalent to applied amplitude $\Delta K\left(=K_{\max }-K_{\min }\right)$. To the latter, the crack surfaces contact when the load is unloaded to $P_{\mathrm{CF}}$, which likes the crack mouth being fully wedged-frozen, and the actual stress intensity factor at the crack tip is still $K_{\mathrm{CF}}$ even though the load is unloaded to $P_{\min }$. So the actual amplitude at the crack tip decreases from $\Delta K\left(=K_{\max }-K_{\min }\right)$ to $\Delta K_{\mathrm{CF}}\left(=K_{\max }-K_{\mathrm{CF}}\right)$, it likes the change in load condition. 


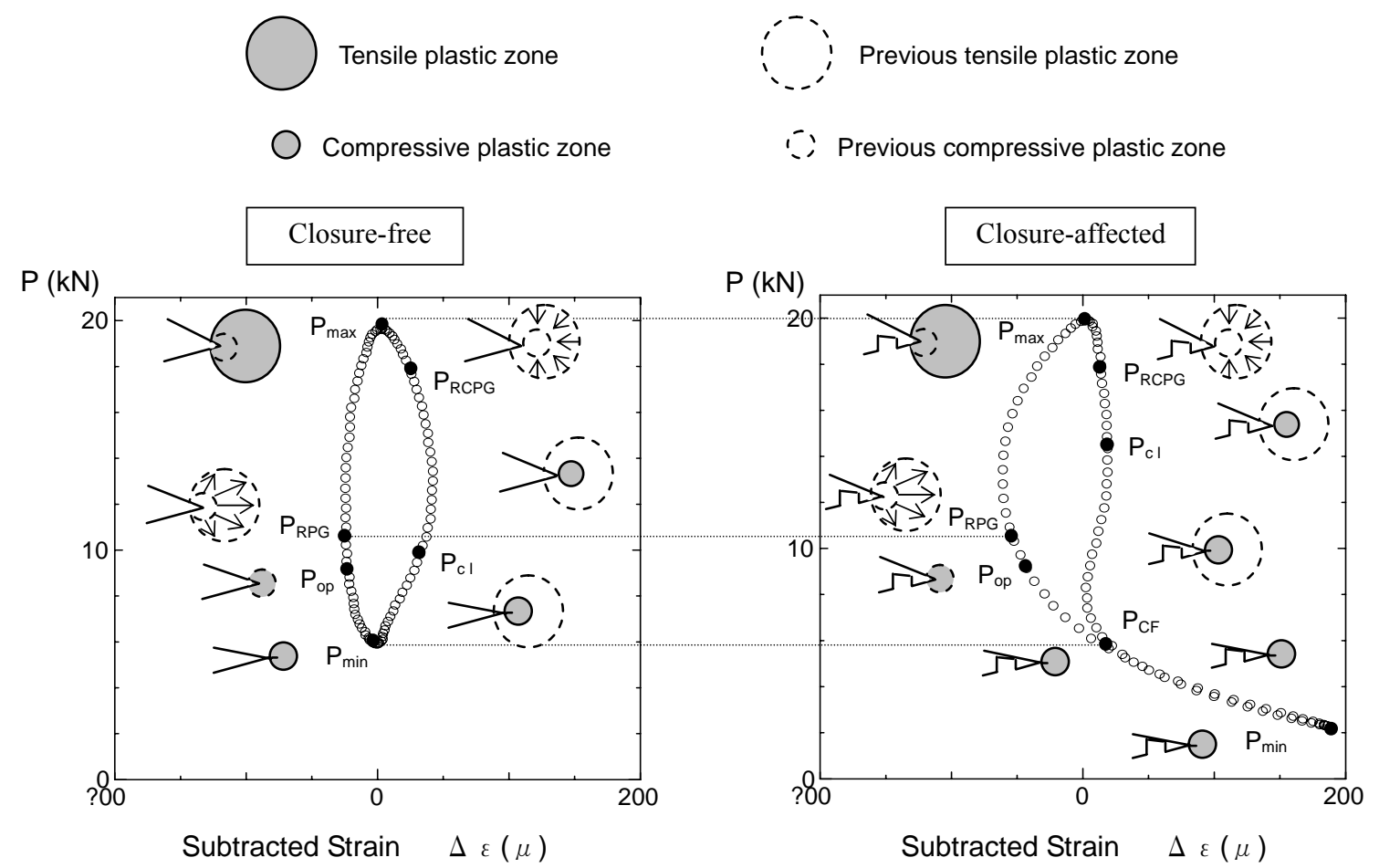

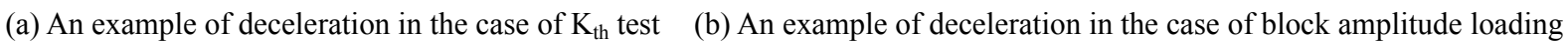

Figure 10. Schematic diagram the influence of crack closure on fatigue crack propagation

According to the relationship between the size of the plastic zone at the crack tip and the square of $K$ in the Ref. [8], if $K_{\max }$ denotes the size of the tensile plastic zone and $\Delta K_{\mathrm{RCF}}\left(=K_{\mathrm{RCPG}}-K_{\mathrm{CF}}\right)$ denotes the size of the compressive plastic zone indirectly, then $\Delta K_{\mathrm{RPG}}\left(=K_{\max }-K_{\mathrm{RPG}}\right)$ represents the overlapped zone of tensile and compressive zones. The plastic deformation energy in this overlapped zone drives a fatigue crack to propagate only [9]. The above tests shows the fatigue crack grows difficultly if there is no completely compressive plastic zone $\Delta K_{\mathrm{RCF}}$, and $\Delta K_{\mathrm{RPG}}$ is not enough yet. Therefore, the reason of fatigue crack deceleration is that the reduction in the actual amplitude causes a decrease in the compressive plastic zone at the crack tip.

\section{CONCLUSION}

Emphasis on the hystersis loop denoting the relationship between loads and strains near the fatigue crack tip, the elasto-plastic behavior at the crack tip is studied under various fatigue test conditions, and the results are as follows.

(1) An alternating change in the tensile and the compressive plastic zones is a requirement for fatigue crack propagation. The crack propagation decelerates in the absence of a sufficient compressive plastic zone at the crack tip.

(2) The route of fatigue crack propagation $P_{\mathrm{RPG}} \sim P_{\max }$ and $P_{\mathrm{RCPG}} \sim P_{\mathrm{CF}}$ plays an important effect in the crack opening/closure behavior, and is also a fundamental reason for causing the acceleration, deceleration and non-propagation phenomena under variable amplitude loading.

(3) The crack closure types and the size of the plastic zone at the crack tip can be speculated according to the loads such as open/closure load on the hysteresis loop obtained by differential, and the fatigue crack propagation behavior can also be estimated quantitatively. 


\section{NOTATION}

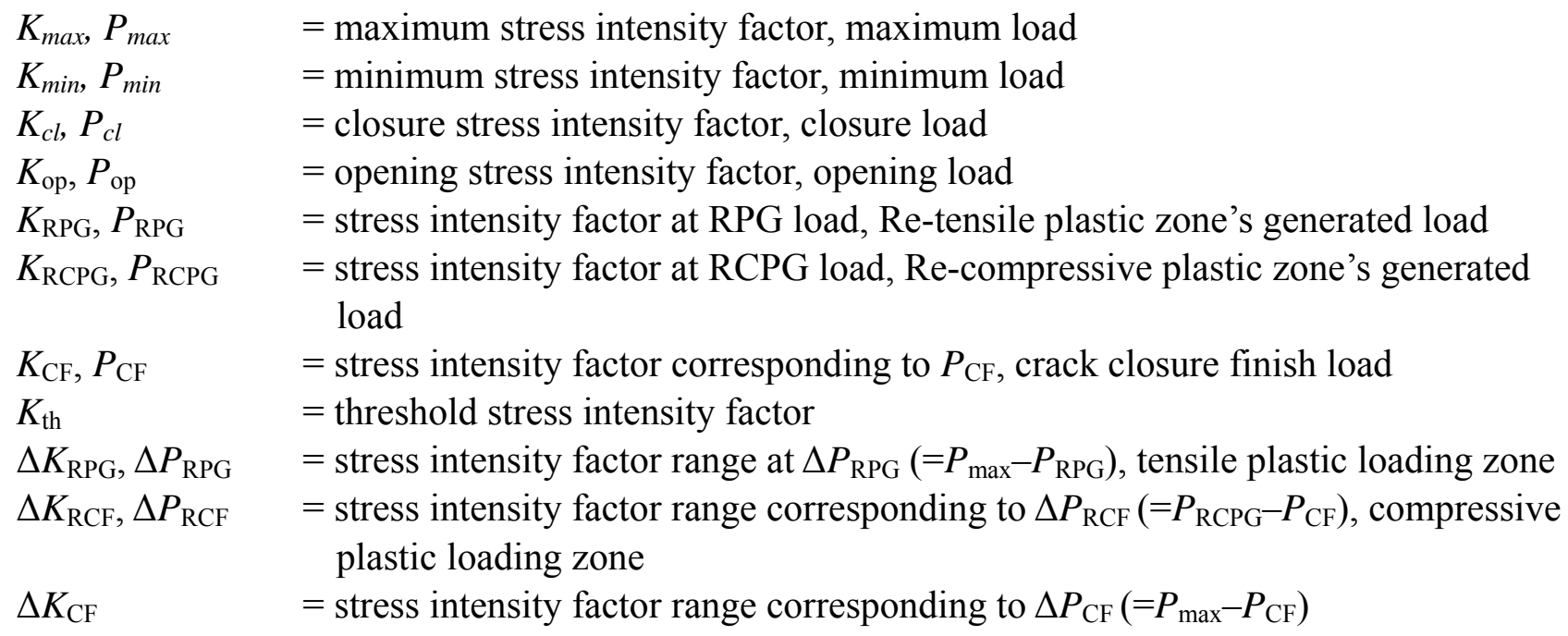

\section{REFFERENCES}

[1] Elber, W., "The significance of fatigue crack closure", In: Damage tolerance in aircraft structures, ASTM STP 486, 1971, pp.230-242.

[2] Stoychev, S. and Kujawki, D., "Methods for crack opening load and crack tip shielding determination: a review”, Fatigue Fract. Engng Maert. Struct., 2003, 26, pp.1053-1067.

[3] Kikukawa, M., Jono, M., Tanaka, K. and Takatani, M., "Measurement of fatigue crack propagation and crack closure at low stress intensity level by unloading elastic compliance method", J. Soc. Mater. Sci. Jpn., 1976, 25, pp.899-903.

[4] Nisitani, H. and Chen, D.H.A., "Consideration on the Unloading Elastic Compliance Method”, Trans. Jpn. Soc. Mech. Eng,. 1985, 51, pp.1436-1441.

[5] Toyosada, M. and Niwa, T., "The significance of RPG load for fatigue crack propagation and the development of a compliance measuring system”, Int J. Fracture., 1994, 67, pp.217-230.

[6] Machida, S., Yoshinari, H. and Makino, H., "Detailed observation of change in strain near fatigue crack tip”, J. Soc. Mater. Sci. Jpn., 1997, 46, pp.138-142.

[7] Katsuta, J., Tetsukawa, S., Kawano, K. and Hidaka, T., "On the Measurement for propagation behavior of fatigue crack using piezoelectric ceramics", The West-Japan Society of Naval Architect, 2000, 100, pp.313-325.

[8] Toyosada, M., "A study of threshold phenomena by residual tensile layer close to the surface of a fatigue crack", The West-Japan Society of Naval Architect, 2002, 105, pp.223-235.

[9] Dugdale, D.S., "Yielding of steel sheets containing slits", J. Mech. Phys. Solids., 1960, 8, pp.100-108. 